Abstracta Iranicacta Iranica

Revue bibliographique pour le domaine irano-aryen

Volume 40-41 | 2019

Comptes rendus des publications de 2017-2018

\title{
Sonja Brentjes. Teaching and Learning the Sciences in Islamicate Societies (800-1700)
}

\section{Alessia Zubani}

\section{(2) OpenEdition}

1 Journals

\section{Édition électronique}

URL : http://journals.openedition.org/abstractairanica/50982

DOI : 10.4000/abstractairanica.50982

ISBN : 1961-960X

ISSN : 1961-960X

Éditeur :

CNRS (UMR 7528 Mondes iraniens et indiens), Éditions de l'IFRI

Référence électronique

Alessia Zubani, «Sonja Brentjes. Teaching and Learning the Sciences in Islamicate Societies (800-1700) », Abstracta Iranica [En ligne], Volume 40-41 | 2019, document 3, mis en ligne le 30 décembre 2019, consulté le 19 avril 2021. URL : http://journals.openedition.org/abstractairanica/50982 ; DOI : https:// doi.org/10.4000/abstractairanica.50982 


\title{
Sonja Brentjes. Teaching and Learning the Sciences in Islamicate Societies (800-1700)
}

\author{
Alessia Zubani
}

\section{RÉFÉRENCE}

Sonja Brentjes. Teaching and Learning the Sciences in Islamicate Societies (800-1700).

Turnhout : Brepols, 2018, 334 p.

1 L'ouvrage porte sur l'histoire des sciences et les pratiques d'éducation des savants dans les sociétés islamiques entre 800 et 1700 . L'étude se structure plus particulièrement autour de l'Égypte, la Syrie, l'Iran et l'Iraq, avec quelques considérations pour l'Anatolie, l'Asie centrale et l'Inde.

2 L'ouvrage comprend huit chapitres. Après une brève introduction (p. 9-15) et un premier chapitre qui fournit une contextualisation historique générale (p. 17-31), l'A. se penche sur la question de l'enseignement des sciences entre le $9 \mathrm{e}$ et le $12 \mathrm{e}$ siècle (p. 33-66). Celui-ci avait lieu dans des maisons privées ou dans les cercles de cour. L'introduction du savoir scientifique ancien dans le monde islamique à l'époque en question est bien mise en valeur. Les chap. 3 (p. 67-76) et 4 (p.77-111) marquent un changement dans les modalités d'enseignement des sciences mathématiques, médicales, " occultes » et de la philosophie naturelle. C'est justement à cette époque que celles-ci sont finalement incluses dans les programmes des écoles de formation avancée et des medersa. Ce changement va de pair avec les développements des traditions régionales. Au chap. suivant (p. 113-146), l'A. se penche sur l'enseignement en dehors des medrasa, c'est-à-dire dans les hôpitaux, les maisons privées et dans le cadre des déplacements et des voyages (qui permettaient aux savants de recueillir des manuscrits, ainsi que de perfectionner leur formation dans les principaux centres culturels). Le chap. 6 (p. 147-185) traite des méthodes d'enseignement et de formation, 
tandis que le chap. suivant (p. 187-221) porte sur la question des encyclopédies et de la classification des sciences. La dernière section (p. 223-262) offre enfin une analyse des ouvrages de mathématiques, de médecine, de logique et de philosophie les plus importants. Des appendices, qui incluent des tables des dynasties et des savants, concluent l'ouvrage.

3 Cette étude constitue une référence importante quant à l'histoire des sciences dans le monde islamique et apporte une contribution essentielle à notre compréhension du sujet.

\section{AUTEURS}

\section{ALESSIA ZUBANI}

Doctorante EPHE, Mondes iranien et indien, Paris 